\title{
Las músicas amerindias del Chaco argentino entre la hibridación y la exotización
}

La musique amérindienne du Chaco argentin entre l'hybridation et l'exotisation Amerindian music of the Argentine Chaco, between hybridization and exoticization

\section{Silvia Citro y Soledad Torres Agüero}

\section{CpenEdition}

\section{Journals}

Edición electrónica

URL: https://journals.openedition.org/jsa/14358

DOI: $10.4000 /$ jsa. 14358

ISSN: 1957-7842

Editor

Société des américanistes

\section{Edición impresa}

Fecha de publicación: 31 diciembre 2015

Paginación: 203-230

ISSN: 0037-9174

\section{Referencia electrónica}

Silvia Citro y Soledad Torres Agüero, «Las músicas amerindias del Chaco argentino entre la

hibridación y la exotización», Journal de la Société des américanistes [En línea], 101-1 et 2 | 2015,

Publicado el 15 marzo 2016, consultado el 24 febrero 2023. URL: http://journals.openedition.org/jsa/ 14358 ; DOI: https://doi.org/10.4000/jsa.14358 


\title{
Las músicas amerindias del Chaco argentino entre la hibridación y la exotización
}

\author{
Silvia Citro y Soledad Torres Agüero *
}

\begin{abstract}
A partir de la obra Qom Llalec («Hijo de los qom ») del músico toba o qom Romualdo Diarte (Formosa, Argentina), que constituye el primer CD de música indígena producido por la Subsecretaría de Cultura de esa provincia, discutimos el impacto de las recientes políticas culturales en las músicas de estos pueblos. La hipótesis es que en esta obra se evidencia la estrategia política del estado provincial por legitimar el imaginario de una « identidad multicultural » que revaloriza al indígena chaqueño, atendiendo así a las demandas de multiculturalismo y patrimonialización de las políticas nacionales y globales. No obstante, los procesos de hibridación, exotización e invisibilización de lo indígena, también revelan las tensiones y desigualdades que persisten entre gobierno, criollos e indígenas, así como las tácticas de estos últimos para afrontarlas. [Palabras clave: música, indígenas, tobas, patrimonio, hibridez.]
\end{abstract}

La musique amérindienne du Chaco argentin entre l'hybridation et l'exotisation. À partir de l'œuvre Qom Llalec («Fils des qom ») du musicien toba ou qom Romualdo Diarte (Formosa, Argentine), qui est devenu le premier CD de musique indigène produit par le Sous-Secrétariat de la Culture de cette province, nous avons discuté l'impact des politiques culturelles récentes dans la musique de ces peuples. L'hypothèse est que l'on peut apprécier dans cette œuvre la stratégie politique de l'État provincial pour légitimer l'imaginaire d'une « identité multiculturelle » qui revalorise l'indigène chaqueño, répondant ainsi aux exigences du multiculturalisme et de défense du patrimoine de politiques nationales et mondiales. Cependant, les processus d'hybridation, d'exotisation et d'invisibilisation de l'indigène révèlent aussi les tensions et les inégalités qui persistent dans les relations entre gouvernement, « criollos » et indigènes, ainsi que les tactiques de ces derniers pour les affronter. [Mots-clés : musique, indigènes, Tobas, patrimoine, hybridité.]

Amerindian music of the Argentine Chaco, between hybridization and exoticization. Starting from the musical piece Qom Llalec ( « Son of the Qom ») of Toba or Qom musician Romualdo Diarte (Formosa, Argentina), which became the first CD of indigenous music produced by the Culture Department of this province, we discuss

* Facultad de Filosofía y Letras, Universidad de Buenos Aires, Puan 480, 4to piso Of 465bis (1406), Buenos Aires, Argentina [scitro_ar@yahoo.com.ar; soledadta@gmail.com]. 
the impact of recent cultural policies in the music of these peoples. The hypothesis is that this musical piece evidences the political strategy of the provincial government for legitimating the imaginary of a « multicultural identity » that revalorizes the Chaco Indians, responding in this way to demands of multiculturalism and patrimonialization of national and global policies. Nevertheless, the processes of hybridization, exoticization and invisibilization of the indigenous also reveal the tensions and inequalities that persist in the relationships among government, creoles and indigenous people, as well as the tactics of the latter to address them. [Key words: music, indigenous people, Tobas, patrimony, hybridity.]

\section{Introducción}

En Argentina, así como en otros países de América Latina, las músicas indígenas circulan cada vez más por complejos entramados constituidos por diversas instituciones culturales y educativas, mercados, prácticas sociales, ejecutantes y públicos. Principalmente en la última década, tanto los organismos multilaterales internacionales como los Estados nacionales generaron legislaciones y políticas culturales que promueven la « salvaguardia » $\mathrm{y}$ 《 revalorización » del « patrimonio cultural inmaterial » de los diversos grupos, y especialmente de los numerosos pueblos indígenas de la región. Ejemplo de ello es la «Convención para la Salvaguardia del Patrimonio Cultural Inmaterial », promulgada por la Unesco en 2003, y en el caso del Estado argentino, de la Ley 26118, sancionada tres años después ratificando esta Convención y adhiriendo a todos sus artículos. Si bien estos nuevos discursos subrayan los aspectos dinámicos de la cultura y la « recreación constante » del patrimonio por las comunidades, diversos autores también señalan las tensiones entre preservación y transformación que surgen en torno a las expresiones activadas como patrimonio, en tanto se convierten en objeto de políticas que involucran la obtención de recursos para evitar su abandono o alteración (Prats 1997; García Canclini 1999; Lacarrieu 2000, 2008; Guigère 2006; Crespo et al. 2007; Citro y Torres Agüero 2012).

Asimismo, estos mandatos institucionales de « salvaguardia » $\mathrm{y}$ 《 preservación » suelen coexistir con mercados culturales en los que la diversidad cultural e incluso el exotismo se han convertido en cualidades valoradas, junto con las tendencias a la mercantilización y espectacularización. Con la ampliación de las industrias del ocio y del turismo, que implicó desde la promoción turística de rituales, festivales y otras expresiones locales hasta la difusión de la denominada World Music, se fue ampliando la circulación y el consumo de las músicas indígenas, especialmente entre clases medias urbanas no indígenas. Estos procesos suelen dar lugar a importantes transformaciones, tanto en la estética como en las significaciones y finalidades asignadas a estas expresiones. De esta manera, hoy se constituyen en producciones culturales que suelen operar como signos estéticos híbridos que dan cuenta de las tensiones entre 
un mandato global multicultural y patrimonializante de « autenticidad » y/o re-producción de un supuesto género tradicional y la hibridez que favorece el mercado cultural contemporáneo, a través de la incorporación creativa, y a veces también coercitiva, de diferentes influencias estéticas hegemónicas.

Si bien en América Latina, ya desde los tiempos de la colonia el arte fue campo de hibridación y mestizaje, especialmente entre movimientos europeos como el barroco y algunas tradiciones indígenas que se expresaron sobre todo en las artes visuales y la arquitectura (Gruzinsky 2000), a partir de los procesos de globalización iniciados a finales del siglo xx, se advierte una intensificación de los procesos de hibridación cultural que alcanza a las diversas artes. El incremento de las relaciones interculturales y diásporas (Clifford 1994; Bhabha 2002) así como la difusión de la ideología del multiculturalismo (Grüner 2002; Zizek 1998), promovieron la « desterritorialización y reterritorialización » de los diferentes bienes culturales (García Canclini 1995); mientras que la difusión de las estéticas posmodernas, con su apelación a la fragmentación, intertextualidad, collage y montaje (Jameson 1991; García Canclini 1990), también favorecieron el surgimiento de nuevas modalidades híbridas. Respecto de las conceptualizaciones sobre la hibridez cultural, recientemente algunos autores han destacado su potencial para superar las formas estáticas y trascendentales de la identidad, constituyéndose así en prácticas transgresoras (Taussig 1987), o también, su capacidad para confrontar con su ambigüedad las categorías de autenticidad y verdad del colonialismo y la modernidad (Bhabha 2002). No obstante, como estos y otros autores (Hannerz 1996; Segato 1999; Anthias 2001) también han destacado, se trata de prácticas desautorizantes o desestabilizadoras de modelos hegemónicos que, sin embargo, se sigue estando obligado a utilizar; por ello, estas hibridizaciones también pueden encubrir jerarquías culturales o prácticas hegemónicas más complejas que es necesario develar.

Teniendo en cuenta este contexto, hemos investigado las políticas culturales que especialmente desde el año 2003 han sido promovidas por la Subsecretaría de Cultura del gobierno de la provincia de Formosa (situada en la región norte del Chaco argentino), las cuales se caracterizan por promover, por primera vez en su historia, músicas y danzas de los tobas o qom y otros indígenas de esa región ${ }^{1}$. Nos centraremos aquí especialmente en una de estas producciones culturales: el CD titulado Qom Llalec (« Hijo de los qom »), del músico qom Romualdo Diarte, en tanto fue el primer CD de música indígena financiado y producido por la mencionada Subsecretaría, en el año 2005. Cabe señalar que una de nosotras dedicó gran parte de sus investigaciones etnográficas

1. Formosa es parte del Gran Chaco, una de las principales regiones geográficas de Sudamerica de clima cálido subtropical. Se extiende por parte de los territorios de Argentina, Boliva, Brasil y Paraguay, entre los ríos Paraguay y Paraná y el Altiplano andino. Los indígenas del Chaco argentino resistieron a la colonización española así como a la instalación de misiones hasta fines del siglo XIX. 
entre 1998 y 2003, a documentar y analizar los procesos de transformación de las músicas y danzas de los grupos tobas del este de la provincia, conocidos como toba takshik (Citro 2003, 2005, 2009, entre otros). Así, esta irrupción del Estado provincial en un área en la que hasta entonces no había intervenido, se convirtió en un hecho novedoso que nos impulsó a iniciar esta reflexión conjunta sobre el proceso de implementación y apropiación de estas políticas culturales, analizando su impacto en los músicos indígenas contemporáneos.

Si bien bajo el término « políticas culturales » suele abarcarse un vasto conjunto de instancias, agentes, instituciones y organizaciones, muchos autores coinciden en destacar que en América Latina, el rol del Estado como gestor cultural ha sido fundamental (García Canclini 1987; Ochoa Gautier 2002; Bayardo 2008) $)^{2}$. También existe un amplio consenso en que estas políticas operan « como un campo organizativo que se puede articular para lograr fines de consolidación o transformación simbólica, social y política específicos » (Ochoa Gautier 2002, p. 215), utilizando de diversos modos a las expresiones culturales, en tanto « recursos » (Yúdice 2002) o « medios » para intervenir activamente en el espacio público (García Canclini 1987; Lacarrieu 2000; Coelho 2000; Escobar et al. 2001; Ochoa Gautier 2002). Por ello, cada vez más, el análisis de las políticas culturales nos plantea el desafío de articular el examen de las dimensiones estético-culturales con las políticas, en tanto la gestión y difusión de ciertas manifestaciones consideradas « culturales », se convierten hoy en un complejo campo para llevar adelante o mediar distintas estrategias y disputas simbólicas y políticas.

En el caso argentino, si bien los estudios antropológicos sobre políticas culturales constituyen un área de notable desarrollo en los últimos años, han sido muy pocos los estudios que focalizan en sus modos de implementación en provincias con población indígena (Roig 1996; Ruiz 2002-2003; Cámara de Landa 2006; Mennelli 2007; Citro y Torres Agüero 2012) y menos aún, los que se centran en el impacto de estas políticas en sus músicas y danzas, de ahí nuestro interés en focalizar aquí en el análisis del mencionado CD.

Ya más específicamente, en lo que refiere al campo de la antropología de la música, es importante destacar que especialmente desde las décadas del 60 y 70 , se ha venido analizando la capacidad de estas expresiones para actuar como poderosos símbolos culturales o índices de identidades, remarcando su dimensión representativa. No obstante, en trabajos posteriores también comenzó a enfatizarse que estas expresiones no sólo serían capaces de condensar

2. Cabe aclarar que en el caso formoseño, la intervención de otros organismos, como las ONGs, en la producción y circulación de las músicas indígenas, ha sido mínima. Ésta se restringió a la elaboración de un CD colectivo donde participó la cantante toba Ema Cuañerí junto con tres cantantes de otros grupos indígenas y al apoyo de algunas actuaciones puntuales de Ema y Romualdo Diarte. Sobre este aspecto, cfr. Citro y Torres Agüero (2012). 
simbólicamente los rasgos de un determinado grupo o contexto social, sino que también son prácticas constitutivas de aquellas realidades socio-culturales de las que participan, tal es lo que se aprecia en las obras de Blacking (1985), Frith (1987), Béhague (1994), entre muchos otros, y para el caso del Chaco argentino, en los estudios de García (1999), Ruiz (2002-2003) y Citro (2003, 2005, 2009). Por tanto, las performances musicales no solo permitirían reforzar o legitimar posiciones identitarias ya constituidas (étnicas, nacionales, de clase y/o género), sino que también pueden intervenir activamente en sus procesos de construcción y transformación, así como en las disputas y estrategias políticoculturales que encaran los diversos grupos y sectores sociales. Dentro de esta perspectiva y retomando también las reflexiones de De Certeau (1988) sobre las relaciones de poder, nos interesa investigar entonces cómo estas músicas y danzas indígenas pueden ser hoy utilizadas « estratégicamente » por los sectores que detentan el control de un espacio de poder, como en este caso el gobierno formoseño, y « tácticamente » por los que se hallan bajo ese régimen, como son los músicos indígenas, para legitimar, o intentar reconfigurar, los imaginarios identitarios étnicos, provinciales y nacionales.

La hipótesis que intentaremos demostrar es que en el CD objeto de nuestro análisis se evidencia la estrategia política del estado provincial por legitimar el imaginario identitario formoseño como « una identidad multicultural » que revaloriza el componente indígena, atendiendo así a los mandatos globales que hoy se imponen a los Estados-naciones democráticos; no obstante, en los procesos de hibridación estética, exotización e invisibilización de ciertos rasgos de lo indígena que advertimos en esta producción, también se revelan (aunque de manera más sutil), las tensiones, conflictos y desigualdades que atraviesan las relaciones político-culturales entre el gobierno formoseño, la población criolla y los grupos indígenas, así como las tácticas de estos últimos por confrontar y reconfigurar ciertos rasgos de esos imaginarios.

Para contrastar nuestra hipótesis, en primer lugar, describiremos los contextos sociales y espacios institucionales en los que hoy se despliegan las músicas tobas, los medios en los que se las difunde y la trayectoria de sus músicos, productores y otros gestores que intervienen en su producción y distribución. En segunda lugar, nos centraremos en la descripción analítica del CD Qom Llalec, atendiendo a los diversos lenguajes estéticos que involucra y a los modos en que se articulan músicas, discursos e imágenes. Una vez efectuada esta descripción, como tercer paso proponemos un análisis genealógico que permita identificar la manera en que ciertos elementos estéticos y significaciones del caso analizado, remiten a otros géneros y prácticas culturales. La intención es poder mapear cómo en estas producciones culturales, ciertos elementos característicos de performances indígenas y no indígenas son des-contextualizados y re-contextualizados, combinados o resignificados, operando como marcas diacríticas indexicales (Turino 1999; Bauman y Briggs 1996); mientras que 
otros elementos que históricamente han sido característicos de estas expresiones, son invisibilizados. Asimismo, nos interesa destacar cómo en las marcas de lo indígena, muchas veces se recurre a estereotipos exotizantes y atemporales, que incluso pueden ser reapropiados por los mismos indígenas, operando a la manera de lo que Spivak (1987) denominó « esencialismo estratégico ». No obstante, retomando a Bhabha (2002, p. 92), cabe aclarar que no se trata de evaluar aquí el posible grado de « deformación » de estos estereotipos sobre lo indígena, sometiéndolos a un juicio previo normalizador, sino más bien de « construir su régimen de verdad » $\mathrm{y}$ " comprender los procesos de subjetivación hechos posibles (y plausibles) mediante el discurso estereotípico », un discurso que, en los casos analizados, se hace carne en sonoridades, letras e imágenes corporales. Como hemos señalado en otros trabajos (Citro 2003, 2009), consideramos que el examen de los modos en que los productores y performers se apropian de estas diversas marcas, nos permite empezar a develar algunos de sus posicionamientos identitarios así como de sus estrategias y tácticas político-culturales para legitimarlos o modificarlos, pues se trata de procesos que no siempre son verbalizados espontáneamente ni son objeto de reflexión consciente por parte de los sujetos. En este sentido, nuestro análisis apunta a examinar las posibles consecuencias o impactos de estas producciones culturales tanto en los imaginarios identitarios como en las relaciones sociales encaradas por los performers.

Nuestro entendimiento de las identidades se aleja entonces de cualquier postura esencialista, remarcando en cambio su carácter interaccional, procesual y dinámico, señalado ya por los estudios pioneros de Barth (1976). Asimismo, desde una perspectiva post-estructuralista, nos interesa destacar cómo las posiciones identitarias se construyen a partir de reiteraciones performativas que suelen involucrar diversas identificaciones (y también desidentificaciones y subversiones) con poderosas matrices de género, clase, raza, etnia y nación, que preexisten al sujeto. No obstante, veremos que es justamente en el contexto de las disputas ideológico-políticas, donde más se aprecian los intentos por fijar esas identificaciones múltiples y cambiantes a un único imaginario, es decir, a una serie de significantes que intentarán hegemonizar aquel significante identitario clave que es objeto de disputa, como es en este caso la definición del « ser formoseño » multicultural y del « toba o qom $»^{3}$.

3. Si bien el carácter imaginario de las comunidades ya fue destacado por Anderson (1993), retomando a Laclau (1996), quien a su vez retoma a Lacan, nos interesa enfatizar cómo estas identidades imaginadas operan a la manera de « significantes vacíos », pues son objeto de disputas entre los distintos grupos que intentan « llenarlos » de un determinado significado y así hegemonizarlo (Citro 2009). 


\section{Los indígenas de Formosa, el Estado y sus políticas culturales}

El territorio formoseño estuvo habitado mayormente por indígenas cazadores-recolectores semi-nómadas, tobas o qom, pilagá y wichi, que durante las primeras décadas del siglo xx comenzaron un proceso de sedentarización, incorporación al trabajo agrícola y conversión religiosa. Así, es recién en esa época que el Estado nacional argentino completó el proceso de incorporación y control efectivo de esos territorios y poblaciones, a través de campañas militares, del establecimiento de fuertes y reducciones estatales, así como del apoyo a las misiones religiosas, el establecimiento de colonos y la construcción del ferrocarril (Braunstein 1983; Wright 2008).

Debido a esta incorporación « tardía » del territorio formoseño respecto de otras provincias argentinas y probablemente también por su lejanía con la capital Buenos Aires, el menor interés económico de sus tierras y su escasa población criolla, Formosa permaneció como « territorio nacional » hasta 1955, año en el que se transformó, como suelen decir sus funcionarios, en una « joven provincia ». En lo que refiere a la legislación indígena, ha sido una provincia pionera en el país, pues en 1984, poco tiempo después de la reapertura democrática, sanciona la Ley provincial 426 (Ley Integral del Aborigen) mediante la cual se creó el Instituto de Comunidades Aborígenes y se dispuso la entrega de títulos a distintas « comunidades ». No obstante, desde ese entonces se han sucedido diversos conflictos con el reconocimiento de los territorios indígenas y el Estado provincial ha profundizado en políticas asistencialistas y clientelares que reproducen situaciones de desigualdad y, especialmente, de dependencia económica de la acción estatal, impactando considerablemente en los modos de organización y participación política de los grupos indígenas, sobre todo entre aquellos que habitan el centro-este formoseño (Citro 2003, 2009; Iñigo Carrera 2006-2007; Salamanca y Tola 2008; Vivaldi 2008; Wright 2008; Cardin 2013). Pese a esta situación, durante la última década, algunos grupos tobas empezaron a generar modalidades de auto-organización política que involucraron asambleas, cortes de ruta y la formación de asociaciones independientes del Estado y de los partidos políticos tradicionales, especialmente del peronismo. En muchos casos, la respuesta del Estado provincial a estas modalidades de acción política así como a los conflictos suscitados, implicó la deslegitimación y persecución de los nuevos líderes, la criminalización de la protesta social, la represión y abuso de las fuerzas policiales, tal es lo que aconteció en la represión de la comunidad toba Nam Qom en 2002 (Vivaldi 2008) y en los cortes de ruta de 2005 y especialmente de 2010-2011 en la comunidad toba de La Primavera (Cardín 2013), en los cuales también quedaron de manifiesto las actitudes discriminatorias hacia los indígenas que aún perviven en parte de la población blanca de la región.

Fue en este contexto de creciente participación y movilización de los tobas que llevó a conflictos con el gobierno formoseño, que este último empezó 
a impulsar más decididamente políticas culturales que intentan enfatizar en el carácter « pluri » o « multi » « cultural » de la provincia, reivindicando el componente indígena, en una perspectiva que se alinea con los mandatos globalizados hoy impuestos a los Estados-Naciones.

Cabe recordar también que desde el 2003, con el inicio en Argentina el gobierno de Néstor Kirchner y luego de su esposa Cristina Fernández, comenzó un período de importantes cambios en las políticas económico-sociales y culturales ${ }^{4}$. Entre estas últimas, se aprecia una posición ideológica, expresada en las declaratorias y programas de la Secretaría de Cultura nacional, que enfatiza en « el carácter multicultural del país, el respeto por las identidades de los pueblos originarios e inmigrantes que lo componen », y que estaría promoviendo la construcción de nuevos imaginarios sobre las identidades nacionales que incluyen más decididamente el componente indígena y lo revalorizan (Bayardo 2008). De este manera, se viene confrontando y reformulando el imaginario nacional que, desde fines del siglo XIX, construyeron las elites gobernantes argentinas, acerca de una nación « blanca » heredera fundamentalmente de las tradiciones europeas (Bartolomé 1987).

Es importante aclarar que en un trabajo anterior (Citro y Torres Agüero 2012), analizamos en detalle la política cultural de la provincia en relación a las músicas indígenas, a partir de la revisión de las legislaciones, programas culturales y medios de difusión oficiales, así como de su relación con las políticas nacionales e internacionales. Por tanto, en el presente artículo, nos limitaremos a señalar solamente algunos rasgos de estas políticas, para indagar específicamente sobre el modo en que estas incidieron en la elaboración del CD Qom Llalec así como en la trayectoria de su autor, Romualdo Diarte. Entre otras cuestiones, en el mencionado artículo analizamos cómo en 2003, la provincia sanciona una nueva constitución « reafirmando la auténtica identidad multiétnica y pluricultural » de la provincia (Preámbulo). No obstante, si bien dentro de esta pretendida concepción multiculturalista se alude a la «preexistencia de los pueblos aborígenes que la habitan » (art. 79, cap. 4), y a que la « realidad cultural » provincial es « pluricultural » y está conformada por « vertientes nativas » y diversas « corrientes inmigratorias » (art. 92, cap. 6), en ningún pasaje del texto constitucional se alude específicamente a esos pueblos indígenas y a corrientes migratorias. Así, se aprecia una invisibilización de estos grupos, en pos de construir una « identidad del pueblo formoseño » como una unidad

4. Ambos gobiernos peronistas revirtieron muchas de las políticas del gobierno peronista de la década anterior (el de Carlos Menem), que habían llevado al país a una profunda crisis económico-política en el año 2001. Entre estos cambios puede mencionarse la ruptura inicial con los principales organismos financieros multinacionales y sus políticas económicas neoliberales, una mayor intervención estatal en la producción y redistribución económica, y una creciente integración económica-política y cultural con Latinoamérica. 
que, si bien reconoce su carácter « pluricultural », no particulariza ni valoriza la diversidad de sus componentes.

Finalmente, en el citado artículo (Citro y Torres Agüero 2012, p. 167-168) también analizamos cómo a partir de 2004, la Subsecretaría de Cultura provincial organiza el « Primer Encuentro de Pueblos Originarios de América », el cual se celebró sólo hasta el 2006; y en 2005 (año de la « Cincuentenario de la provincialización de Formosa »), comienza a apoyar las actividades de Romualdo Diarte y otros músicos indígenas como Ema Cuañeri, Pilancho González y el grupo toba Qom Amistad $^{5}$, aunque como veremos, este apoyo también ha mermado considerablemente en la actualidad.

Una de las conclusiones a las que arribamos a partir del análisis de estos y otros eventos y documentos oficiales, es que si bien en ellos se intentaba legitimar a un « ser formoseño multicultural », también se constataba una fuerte tendencia a invisibilizar a los indígenas contemporáneos, por ejemplo, cuando en los documentos se evita utilizar sus autoadscripciones étnicas como pueblos tobas, pilagá o wichi y se las reemplaza por términos generalizadores como « culturas etnográficas » o « vertientes nativas » (Citro y Torres Agüero 2012, p. 164). Finalmente, dentro de este discurso oficial multicultural y celebratorio de la diversidad, advertimos también la tendencia a asociar a los indígenas a un genérico « pasado tradicional », que se diluiría en ese « armonioso » melting pot actual que sería el « ser formoseño », fusionando las multiplicidades en una identidad única que, según nuestra hipótesis, tiende a enmascarar los conflictos y tensiones surgidas de las desigualdades sociales y de la discriminación.

\section{Una aproximación a la música toba y la trayectoria de Romualdo Diarte}

Aquello que hoy suele denominarse « música toba » abarca diferentes expresiones que los indígenas asocian a su música y « cultura antigua », término con el que refieren a los estilos de vida previos a su conversión religiosa a alguna de las modalidades del cristianismo presentes en la región: principalmente el denominado evangelio - con influencias pentecostales - en el este, el anglicanismo en el oeste y, en menor medida, el catolicismo (Wright 2008; Citro 2009). A través de la evangelización y la incorporación de los tobas al mercado de trabajo rural, y luego, con el acceso a los medios masivos de comunicación y las nuevas tecnologías de la información y la comunicación, se introdujeron nuevos géneros musicales (desde los himnos evangélicos al folklore regional,

5. Este último grupo, en el año 2009 también recibió el apoyo de la Subsecretaría para editar su primer CD Am Maye. En el oeste formoseño, encontramos la colaboración al proyecto del coro wichí Sacham, para la edición del libro digital Wichi Tenkai (2009), dirigido por Sergio Aschero, quién imparte talleres de formación musical a través de los cuales jóvenes wichí compusieron canciones en lengua materna, aplicando el "Sistema Numerofonía » creado por el mismo Aschero. 
la cumbia y el reggaeton), así como instrumentos musicales (desde guitarras y bombos a teclados electrónicos), usos de la voz y estilos de actuación. En este proceso, también se han generado nuevos usos sociales y resignificaciones de las músicas y danzas, como la grabación y comercialización de Cds y, más recientemente, de las filmaciones de los grupos de música y danza de las iglesias indígenas (Citro 2005).

La conversión al evangelismo condujo al abandono de la performance pública de muchas expresiones vinculadas a rituales y festividades del pasado que fueron duramente criticadas por las iglesias, tal es el caso del Nmi, término que refería a los canto-danzas de los jóvenes solteros, y también sus ejecuciones del nvique o « violín de lata », destinadas a seducir a las mujeres; los cantos-danzas con el nasotaGalaqte o palo sonajero de las mujeres en los rituales de iniciación femenina; y los cantos chamánicos con el ltegete o sonaja de calabaza ${ }^{6}$. Aún con estas limitaciones y discontinuidades en las prácticas, encontramos que algunos de los rasgos musicales de estos géneros persistieron en la música evangélica, especialmente en los Coritos y la Rueda, dando lugar a procesos de hibridación musical y coreográfica que abordamos en diferentes trabajos (Ruiz y Citro 2002; Citro 2005; Citro y Cerletti 2009) ${ }^{7}$.

A pesar de la vitalidad y hegemonía que hoy adquiere el movimiento evangélico entre los tobas y de la deslegitimación que provocó sobre sus prácticas musicales y dancísticas anteriores, ya desde el año 2000, en nuestros trabajos de campo en La Primavera y Nam Qom, comenzamos a notar el interés de algunos jóvenes músicos toba del Evangelio, por conocer y « recuperar » (tal es el término que solía escucharse) sus músicas y danzas. No obstante, como vimos, fue recién en 2005 que la Subsecretaría de Cultura comenzó a incorporar a unos pocos músicos tobas en sus programas oficiales.

Pasemos ahora a caracterizar la trayectoria de Romualdo como músico en estos diversos campos. Romualdo tiene actualmente treinta y siete años y nació en la comunidad rural de San Carlos, donde aprendió a tocar la guitarra en el marco de los grupos de música autodidactas de las iglesias del Evangelio. Años más tarde, se trasladó a Formosa capital para estudiar el colegio secundario y comenzó a participar en un coro escolar coordinado por Ema Cuañerí, que incluía algunos « temas autóctonos » además del repertorio folklórico. Según Romualdo, fue en ese contexto que se le « despertó el interés por la propia música ». Ema Cuañerí, además de maestra es una reconocida « cantautora toba » (así se autodefine), que se ha dedicado a recopilar cantos y danzas « antiguas »

6. Para una caracterización detallada de estos instrumentos y músicas puede verse Ruiz (1985) y Ruiz y Citro (2002).

7. La música evangélica toba hasta el momento no ha sido objeto de políticas de promoción cultural estatales, seguramente debido a su intensa hibridez musical y contenidos cristianos en las letras. No obstante, como veremos, en las expresiones hoy consideradas « tobas » también se advierten procesos de hibridación, aunque menos marcados. 
y ha realizado numerosas actuaciones. Ella nos contó que la primera vez que escuchó aquel coro de jóvenes, se « sintió liberada » y que su « misión estaba cumplida », pues pensó que de allí surgiría algún joven que podría continuar con la música toba. Esta continuidad era una preocupación para ella, porque se « sentía sola lidiando » con la recuperación de la música tradicional y temía que si « moría », no hubiese quién la continuara. Romualdo, con la ayuda de Ema, se convirtió entonces en el continuador de este legado, así, ambos coinciden en que su música se basa en cantos que « escucharon de los abuelos », y que eran utilizadas especialmente en los diferentes « rituales » (no evangélicos) del pasado.

Romualdo, una vez terminado el colegio secundario, ingresó al instituto de profesorado de música provincial, y en ese nuevo contexto profundizó el interés por su propia música, aprendiendo a tocar el nvique o « violín de lata » con el músico César González de San Carlos, su comunidad natal. Este instrumento es construido artesanalmente por los tobas - con una sola cuerda y el arco de crin de caballo y con la caja de resonancia de lata - y era ejecutado solamente por los hombres, principalmente en el contexto de los antiguos encuentros nocturnos entre jóvenes. Por eso, hoy quedan muy pocos ancianos que como César ejecuten el nvique.

Romualdo, una vez recibido de profesor, comenzó a trabajar como maestro de modalidad aborigen y profesor de música en la escuela primaria y secundaria del Barrio toba de Nam Qom, cercano a la capital formoseña, y hasta el momento, es el único indígena toba formoseño que posee un título de profesor de música otorgado por una institución oficial.

La trayectoria artística de Romualdo es extensa, luego de participar en algunos conjuntos musicales, especialmente a partir del 2004 comenzó a actuar como solista en diversos eventos, entre ellos los impulsados por el programa La Voz de los sin Voz (con apoyo de la Unesco y la Secretaría de Cultura de la Nación), el Congreso Nacional de Cultura y el Programa Música para todos (organizado por la Secretaria de Cultura de Nación), el Encuentro de Pueblos Originarios de América y otros encuentros de carácter local (como el Encuentro de Jóvenes Artistas, Festival de la Corvina, Festival del Pomelo) organizados por la Subsecretaría de Cultura de Formosa. Asimismo, Romualdo suele brindar talleres y conferencias sobre la música toba y, además, realizó dos cortometrajes sobre el tema, con el apoyo del Fondo Nacional de las Artes, la Universidad de Buenos Aires y las antropólogas participantes del proyecto, Torres Agüero y Sarraute Yamada ${ }^{8}$.

8. En 2007, concretamos la realización de un taller audiovisual con Romualdo y otros maestros de modalidad aborigen, interesados en el uso del video como una herramienta de documentación, investigación y transmisión sobre las propias expresiones artístico-culturales, con el fin de producir un material audiovisual didáctico y de difusión para las escuelas y la comunidad. El objetivo fue buscar y registrar audiovisualmente, en tres comunidades rurales toba del interior de Formosa, músicas y danzas previas a la llegada de los criollos 
Ema ha acompañado y apoyado decisivamente la carrera de Romualdo como músico y docente, impulsando su incorporación a la Subsecretaría de Cultura, donde ella ya se desempeñaba desde 2005 - primero como colaboradora de la revista Ser Formoseño, y luego como coordinadora del área de Artesanías. En este marco, a Romualdo le asignan seis horas semanales para la « investigación sobre su cultura », por lo cual ha venido participando en diversas actividades, como la realización de talleres extracurriculares de música toba para la escuela de Nam Qom y otras de la zona (en el marco del programa provincial Escuela Abierta), y junto con Ema, cuando la Subsecretaría se los solicita, participan en espectáculos o en alguno de los Festivales antes mencionados. No obstante, en los últimos años la situación inversa se ha tornado más difícil. Es decir, cuando los músicos o incluso también artesanos indígenas solicitan « apoyo » a la Subsecretaría, por ejemplo para solventar gastos de viaje para concurrir a actuaciones o exposiciones, dar clases o participar en un encuentro, no suelen obtenerlo. Según la percepción de algunos tobas, esta estrategia oficial sería una respuesta a la creciente conflictividad entre algunos de sus líderes y el gobierno provincial, a la manera de un escarmiento no explícito. En un sentido similar fue interpretado por algunos tobas el hecho de que el Festival de Pueblos Originarios no se efectuara más: « para muchos el Festival se inició por política, para tapar la racia (represión policial) de Nam Qom... », pero cuando empezaron a « reclamarle al gobierno, ya no lo quisieron hacer más »... De hecho, cabe destacar que cuando consultamos a las autoridades sobre los motivos que llevaron a la suspensión de este Festival, no obtuvimos una respuesta clara, más que la referencia a una inundación que había afectado a algunas comunidades de la provincia. Estas experiencias muestran cómo las modalidades clientelares antes mencionadas también atraviesan las políticas culturales provinciales, otorgándoles un carácter coyuntural, que responde más a los vaivenes de las alianzas o conflictos políticos del gobierno que a programas o proyectos culturales previos consensuados por un Estado participativo. En suma, como reflexionaba otro músico toba: « ¿Por qué se acuerdan de nosotros un 19 de abril o un 12 de octubre ${ }^{9}$, si todo el año existimos...? »

A continuación, analizaremos el primer y por ahora único CD de Romualdo.

y misioneros. El producto final del taller fue dos cortometrajes: «ÑamqtaGa ca César (Visitando a César) », referido precisamente a César Gonzalez, el maestro de nvique de Romualdo, y «Potai Napokna, Colonia la Primavera » que fueron exhibidos en distintas comunidades, festivales de cine y video y en instituciones culturales afines. Videos disponibles en: https://vimeo.com/5232705 y https://vimeo.com/5232075

9. Estas fechas refieren, respectivamente al « Día del Aborigen » y al « Día de la Diversidad Cultural » (que hasta el 2010 fue denominado « Día de la Raza »). 


\section{Músicas, discursos e imágenes del CD Qom Llalec}

Como ya adelantáramos, el CD de Romulado Diarte Qom Llalec constituye la primera edición de « música toba o qom » ejecutada por indígenas formoseños, con el apoyo de un organismo estatal provincial. Es importante señalar que en el caso de la vecina provincia de Chaco, donde también habitan otros grupos tobas, existen antecedentes de políticas culturales hacia estos grupos, que incluyeron ediciones en CD de su música, las cuales han influido a los músicos tobas formoseños. Nos referimos al coro toba Viri Nolka (con un CD de 1960 que luego fue reeditado), y especialmente al coro Chelaalapi creado en 1962 (Roig 1996) y que lleva ya tres CDs editados. Asimismo, desde el 2001, el grupo Tonolec ha jugado un rol fundamental en la difusión de estas músicas, pues si bien está constituido por una joven cantante mestiza chaqueña, Charo Bogarín, y Diego Pérez, un músico blanco, según sus propias definiciones, propone una « fusión » entre la « música étnica toba, el folklore y la música electrónica ${ }^{10}$.

En Qom Llalec, Romualdo ejecuta la voz y el nvique o « violín de lata », mientras que un músico criollo, Pablo Irala, ejecuta guitarras, bajos, percusión y sintetizadores, y fue quien realizó los arreglos musicales y la producción general, como dueño del estudio en donde se realizó la grabación. Pablo Irala pertenece a una familia de músicos reconocidos y con un estrecho vínculo con todas las actividades culturales que promueve el gobierno formoseño. Como veremos, el rol de Pablo Irala ha sido clave en la forma final que ha tomado esta producción musical, aunque esto no sea muy visibilizado en el CD, pues su participación es mencionada en letras muy pequeñas en la contratapa, siendo la imagen y nombre de Romualdo el protagonista visual del CD. La Subsecretaria de Cultura financió las horas de grabación en el estudio de Irala así como las duplicaciones del CD, pero no pagó ningún tipo de honorarios a Romualdo. Al quedar enmarcado en la Colección por el Cincuentenario de la provincialización de Formosa, el CD fue distribuido gratuitamente por la Secretaría, entre diversos organismos así como festivales provinciales y nacionales. En este sentido, Romualdo nos comentaba que quisiera poder reeditar esta obra así como grabar nuevos temas, para poder difundir mejor su música, pero hasta ahora no ha logrado recibir el apoyo necesario para hacerlo.

El repertorio del CD combina dos tipos de piezas musicales que se van alternando. Por un lado, las seis piezas de número par son melodías con nvique,

10. Aún cuando Charo posee ascendencia guaraní, ella estudió la lengua y la música toba con el Coro Chelalaapí. Así, Tonolec se convirtió en uno de los primeros grupos de Argentina que mixturan la música electrónica con una música indígena local, utilizando para el canto el mismo lenguaje nativo. En los últimos años el grupo ha ganado gran popularidad y ha sido impulsado también por la Secretaría de Cultura de Nación, pues fue invitado a participar de importantes actividades, entre las que se destacan los Festejos por el Bicentenario en 20102011 (Citro y Cerletti 2013). Sobre este grupo ver http://www.tonolec.com.ar 
la mayoría sin canto, que en su estructura melódica se asemejan a los estilos musicales tobas " antiguos » documentados en las comunidades (Ruiz y Citro 2002; Citro y Cerletti 2009), y que fueron identificadas como « ancestrales » por Romualdo. Según nos explicaron tanto Romualdo como Ema, la música ancestral es para ellos « la que se transmite de generación en generación. Son las recopilaciones que tenemos de nuestras familias [...]. Estos cantos expresan la cultura, la relación con la naturaleza, con el hombre, en general no tienen textos-letra, o los textos-letra son muy breves y repetitivos [...] son pentatónicos ${ }^{11}$ ». Si bien los temas « ancestrales » del CD de Romualdo seguían estas características, también constatamos que a partir de los « arreglos musicales », se introducían modificaciones, como los acompañamientos con percusión (con diferentes bombos, algunos producidos con sintetizadores, y sonajero de pezuñas) y bajo electrónico, que permiten acercar estos temas a la música popular actual, remarcando los pulsos y utilizando sonoridades electrónicas cuyos timbres resultan más habituales al oído contemporáneo ${ }^{12}$. Asimismo, en el inicio de uno de los temas, se incluye una breve introducción melódica con sintetizador.

Todos estos temas instrumentales son precedidos por explicaciones verbales en español, que dan cuenta de su sentido, siendo esta una modalidad que ya había adoptado el coro Chelaalapi en sus grabaciones anteriores. Veamos algunas de estas explicaciones grabadas, así como otras que nos brindó Romualdo en una de nuestras entrevistas. Los temas 2 (Pioq dalo o Aguaracope) y 6 (TaGaiko o Amambe común) son toques de nvique que aprendió con su maestro César González y, como cuenta en la grabación, « imitan » cantos de animales de la región; el 8 (Alo noinaGac o Llanto de mujer) es una composición propia de Romualdo que, retomando motivos míticos, refiere a una « mujercita que lloraba porque su amado la había abandonado porque tenía que cumplir una misión para el bien de su pueblo », y tanto lloraba, « que sus llantos quedaron grabados en la naturaleza y hoy en día podemos traerlos a través del nvique ». Los temas 4 y 10 son versiones instrumentales en nvique de cantos ya grabados por el coro Chelaalapi: en Ayalaic LavoGolec (Flor de Lapacho), se relata que « el abuelo le dice a sus nietos que observen la naturaleza porque ella es nuestra guía, cuando ven florecer el lapacho significa que ha llegado el momento de la pesca del dorado »; en La'ñaGashe lashe (la suroesteña), se introduce el tema diciendo que « es una danza de amistad que se practica en el tiempo de la recolección

11. Esta referencia al « pentatonismo » que señala Romulado, proviene de sus aprendizajes musicales formales en instituciones de la provincia, en las cuales aún se siguen utilizando estas y otras ternimologías tradicionales de connotaciones evolucionistas.

12. Cabe destacar que la música folklórica argentina contemporánea se ve cada vez más atravesada por la instrumentación electrónica del rock (guitarras y bajos electrónicos, sintetizadores). Asimismo, Roig (1996) analizó como ya en el coro Chelaalapi se incorporaban instrumentos de percusión que no solían acompañar al nvique en el pasado. 
de frutos silvestre durante la cosecha de algarroba », y según nos explicara Romualdo, sería un canto-danza de nmi. También el último tema, Yasosheole (Mi sobrina), es un canto-danza de nmi conocido entre los tobas formoseños.

En contraste con estos « temas ancestrales », las canciones de número impar son definidas por Romualdo como « composiciones actuales o recientes » de su autoría, y todas son cantadas en toba y acompañadas en las hojas internas del $\mathrm{CD}$, con una breve explicación escrita en español ${ }^{13}$. Tanto la instrumentación de estos temas (guitarra, bajo eléctrico, percusión y sintetizadores) como su estructura melo-rítmica, remiten a los géneros folklóricos y populares hoy en boga en la región mientras que los títulos de los temas y las líricas en toba, se constituyen en índices que remiten a la música indígena, aunque los géneros tradicionales, como suelen decir los tobas, eran « sin letra », pues repetían unas pocas palabras o frases.

Este modo de estructurar músicas y discursos en el CD, parece evidenciar el impacto de los procesos de escolarización, pues mientras los temas « ancestrales » son precedidos por relatos orales de historias específicas, los temas « recientes » son acompañados de explicaciones escritas que apelan a una mayor abstracción conceptual. Por ejemplo, sobre el tema 3, NauGo (Primavera), se escribe: « ha llegado el momento de la naturaleza, su fuerza, su color y su aroma. El paisaje se vuelve más sonoro, más colorido, y hay más movimiento natural, donde también el ser humano es cómplice »; sobre el 9, Hua'api la 'añaGac (Fuerza ancestral): « La canción expresa la fuerza ancestral del Pueblo TOBA que sabía enfrentar los peligros de la naturaleza »; y sobre el 11, Vi 'i (Año nuevo): « después de la primavera abunda la cosecha de frutos silvestres. Esto sucede siempre cuando se mantiene una armonía entre el hombre y la naturaleza ».

Como puede apreciarse, en las explicaciones de Romualdo se nota su énfasis en trasmitir el tipo de relaciones que los qom tendrían con la « naturaleza », su interés por « observarla », « imitarla », dejarse « guiar » por ella y mantener relaciones « armoniosas ». Según nos comentara, cuando lo invitan a dar alguna clases frente a niños o adolescentes blancos en las escuelas de Formosa, al principio ve en sus caras como que « hay burla y discriminación », pero « cuando comienzo a explicarles, le van cambiando las caras [...], cuando les hablo del cuidado de la naturaleza, eso les gusta a ellos... Les digo que el algarrobo es como nuestro hermano, que tiene vida, como nosotros, que las flores son nuestras hermanas, que hacen bien a la mirada, y que por eso hay que cuidar a la naturaleza... y terminamos cantando todos juntos... » Así, a partir de su

13. Si bien el CD no se encuentra disponible online, puede apreciarse una ejecución de Romualdo Diarte en nvique junto con Ema Cuañeri, en https://www.youtube.com/ watch? $=9$ hFSWDOPVO4 (consultado 6/12/14), de un tema de tipo « ancestral ». Asimismo, en https://www.youtube.com/watch?v=Ljxxb4YQuBs (consultado 6/12/14), se aprecia una versión libre realizada por un coro de la provincia de Formosa, del tema NauGo, que es una de las « composiciones actuales o recientes » de Romualdo, grabadas en su CD. 
experiencia docente, Romualdo percibió el interés de los criollos por este aspecto de la cultura toba ligado a la cosmovisión cazadora-recolectora, los cuales son plausibles de asociarse con los hoy muy difundido discursos ecologistas y de la Nueva Era. Por tanto, en la transmisión de su música, tácticamente enfatiza en estos discursos que poseen una buena acogida en el público.

En lo que respecta a la composición musical, estos temas « recientes » evidencian la importante incidencia de Irala, pues fue este músico criollo el que ejecutó los diversos instrumentos allí utilizados, además de efectuar los arreglos. En una entrevista, Irala nos comentó: « Este trabajo es una fusión del folklore y lo puro de la música toba. No es un disco tradicional toba, partiendo desde la instrumentación misma. Es una mixtura del folklore con la música toba, ya que temas tradicionales de la música toba fueron arregladas con tonalidades y modos más elaborados. »

Estas transformaciones se vincularían con lo que Romualdo también nos dijo en otra charla, acerca de que el « gusto del mercado » tiene mucho más « éxito » y es más fácil de « vender » y nos daba el ejemplo de que « el folklore... tiene más aceptación en la sociedad [...], pero con la música indígena no hay oferta », y agregó: « La sociedad no toma conciencia. Se habla de la diversidad, pero ¿donde está la diversidad?... Por ejemplo, el grupo Qom Amistad fue dejando lo étnico y dedicándose más al folklore. Tiene más aceptación en la sociedad... al público hay que educarlo. »

Como puede apreciarse, estas hibridaciones con el folklore son percibidas por Romualdo como tácticas para insertarse en un mercado que reconoce con otros « gustos » musicales. No obstante, pensamos que en las explicaciones orales y escritas que acompañan cada tema, también puede percibirse su intención de « educar al público », en su preocupación por transmitir los sentidos, orígenes y fines sociales de los diferentes géneros musicales. Asimismo, esto nos muestra las diferencias entre los significados, usos rituales y sociales involucrados en las prácticas musicales indígenas, y los usos habituales de las músicas de la modernidad occidental, en tanto estas últimas han estado orientadas primordialmente al placer o el entretenimiento, dentro de una concepción estética en la cual las artes debían constituirse en una esfera autónoma del resto de las prácticas sociales. Esta diferenciación también es en cierta forma percibida por Romualdo, pues al ser consultado sobre por qué algunas de estas explicaciones fueron grabadas en forma oral mientras que otras fueron escritas, nos contestó: « para no poner toda la explicación al principio, porque muchos solo quieren escuchar la música... »

Finalmente, en otra entrevista en la que charlábamos con Romualdo sobre los diferentes tipos de músicas, consideró que algunos de estos temas podrían denominarse también como « música autóctona qom », ya que « tienen origen en música ancestral pero siempre hay una incorporación nueva por parte del músico... hay una fusión o intervención del músico ». Un ejemplo sería el 
tema « Fuerza Ancestral » en el que según nos explicaba se « basó en la lengua qom... ritmo qom y es pentatónico », pero introdujo instrumentación criolla como la guitarra y el teclado. Así, la fusión implica para Romualdo una síntesis creativa entre aquellas músicas ancestrales heredadas de sus antepasados y la « intervención » que él como joven músico formado en diversos ámbitos (desde las iglesias indígenas, los coros escolares al instituto del profesorado de música) puede introducir en ellas.

En el caso de Irala, la hibridación es planteada como una fusión o mixtura de lo « tradicional o puro toba » con modos « más elaborados » que pertenecerían al folklore, lo cual parece corresponderse con la estrategia oficial de promocionar una identidad multicultural que, no obstante, enmascara desigualdades: en este caso, entre músicas concebidas como « más elaboradas » que otras, y entre los múltiples instrumentos ejecutados por el criollo (los cuales, cabe aclarar, también podrían haber sido ejecutados por Romualdo), y un único instrumento tradicional ejecutado por el indígena.

Pasemos ahora al análisis de la gráfica del CD, que como el mismo Irala señala, es también una parte fundamental en la conformación de este producto artístico: «Se trabajó en todo lo referido al disco siempre en forma conjunta, se define un concepto en la gráfica que identifique en principio lo que el disco lleva dentro. Un mismo concepto que acompañe lo que uno va a escuchar y se entienda desde el momento en que uno ve el disco, ya que en varias oportunidades primero llega por los ojos y después por el oído. »

En lo que refiere a la imagen corporal de la tapa, en la fotografía de Romualdo puede apreciarse un gesto serio que trasluce un tono muscular tenso y una impresión de inmovilidad, reforzada por la postura rígida de la espalda, los brazos y las manos y por la posición de piernas cruzadas sobre el piso, que a su vez remite al imaginario occidental del « sentarse como indio », tan difundida en las películas de Hollywood y de ahí a otros ámbitos ${ }^{14}$; asimismo, la presencia del nvique delante, refuerza la asociación con lo indígena. En este mismo sentido, la imagen de Romualdo se inserta en un fondo en el que se destaca la franja vertical izquierda que corresponde a un tejido artesanal con predominio de tonalidades marrones, a menudo asociadas con la tierra y lo indígena. No obstante, unos pocos elementos también hibridizan esta imagen corporal y la acercan a la de los actuales jóvenes criollos: tal es el caso de la vestimenta característica de los músicos del folklore (jean, camisa blanca y chalecos con tejidos artesanales, en este caso del muy difundido chaguar, proveniente de los indígenas wichi de la región) y los tratamientos aplicados al cuerpo, pues Romualdo lleva el pelo largo suelto (como lo hacían los antiguos indígenas pero

14. Por ejemplo, en el contexto educativo argentino, en los primeros años se suele utilizar la frase « sentarse como indiecitos », para aludir a esta posición corporal. 
también algunos jóvenes criollos contemporáneos) $)^{15}$ y una pequeña barba sobre su mentón (que no es característica de los tobas). Asimismo, abajo a la derecha se coloca un moderno logo que remite a la « Colección del Cincuentenario de la Provincialización de Formosa ».

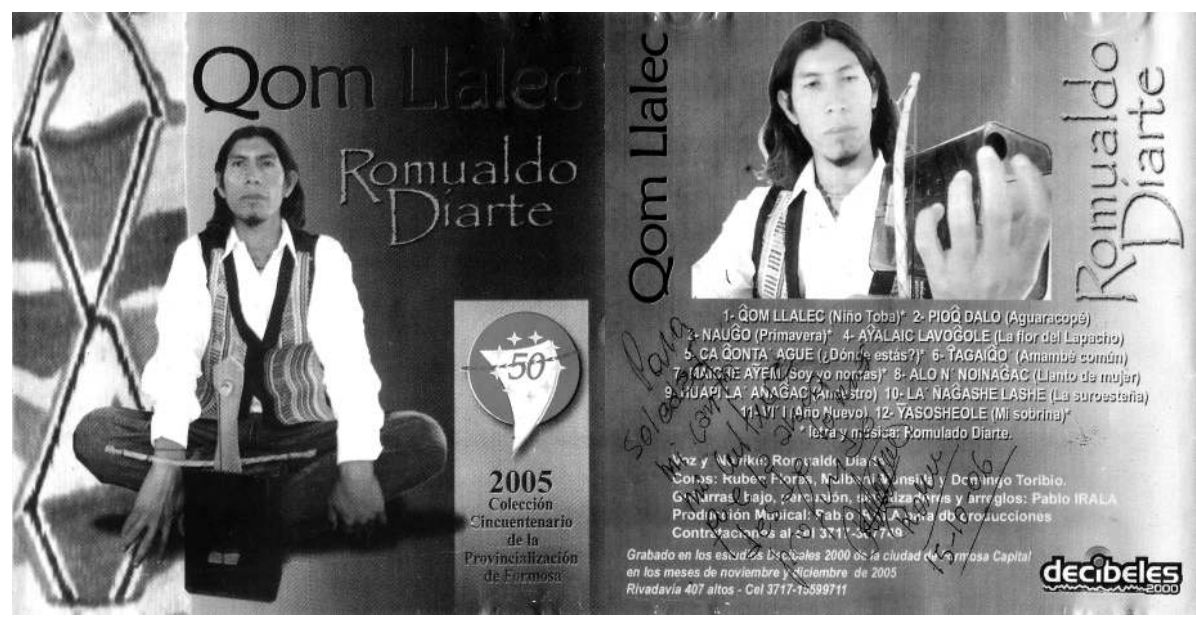

Fig. 1 y 2 - Tapa del CD Qom Llalec y contratapa (con dedicatoria del músico a una de las antropólogas).

En la contratapa se aprecia la continuidad de las tonalidades marrones para el fondo y otra fotografía de Romualdo, esta vez, ejecutando el nvique, en una toma de primer plano con gran angular, que destaca su mano sobre el violín. Así, esta imagen continúa la asociación con lo indígena, pero brindando una impresión más dinámica, que contrasta con la fijeza e inmovilidad de la tapa.

En la tercer fotografía que se encuentra en el interior del CD, Romualdo aparece en un primer plano de perfil, con una mirada que se dirige por encima de la línea del horizonte, lo cual produce una impresión de mirada esperanzada hacia el futuro, que se condice con las significaciones y emociones expresadas en su texto: « Es una gran satisfacción para mí, poder expresarme en mi propia lengua y difundir mi cultura que está viva a pesar del sometimiento de tantos años. Estas canciones expresan el pensamiento de mi pueblo sobre la naturaleza, el amor y la vida. »

15. Actualmente, son pocos los jóvenes tobas que optan por esta estética coporal, de hecho el uso del pelo corto en los varones ha sido una práctica promovida por los distintos procesos de misionalización, como rasgo civilizatorio. 


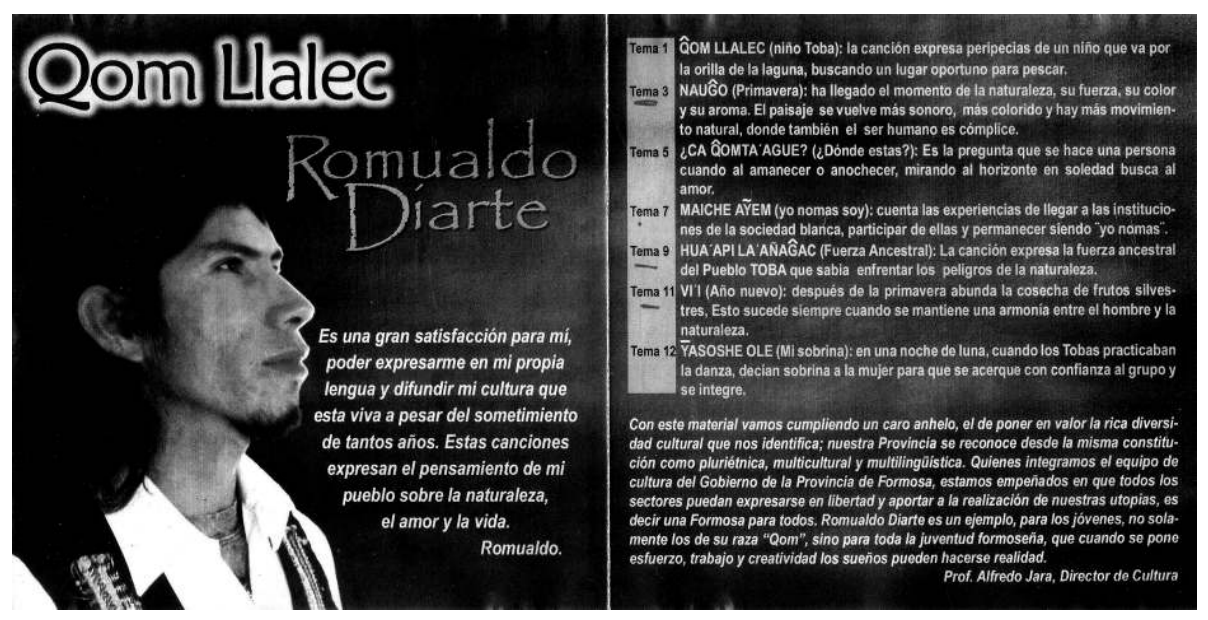

Fig. 3 - Interior del CD Qom Llalec.

Esta satisfacción y especialmente el carácter esperanzador, es también remarcado por las palabras del Subsecretario de Cultura que son incluidas en el CD, y que apelan a términos como « anhelo », « sueños » y « utopías »:

Con este material vamos cumpliendo un caro anhelo, el de poner en valor la rica diversidad cultural que nos identifica; nuestra Provincia se reconoce desde la misma constitución como pluriétnica, multicultural y multilingüística. Quienes integramos el equipo de cultura del Gobierno de la Provincia de Formosa estamos empeñados en que todos los sectores puedan expresarse en libertad y aportar a la realización de nuestras utopías, es decir una Formosa para todos. Romualdo Diarte es un ejemplo, para los jóvenes, no solamente para los de su raza « Qom » sino para toda la juventud formoseña, que cuando se pone fuerza, trabajo y creatividad, los sueños pueden hacerse realidad.

Así, no sólo se intenta promover las expresiones musicales tobas, sino que invirtiendo los modelos tradicionales que impulsaban a la aculturación del indígena, ahora en cambio se lo revaloriza como ejemplo para « toda » la juventud formoseña, desde este imaginario identitario que busca reforzar la multiculturalidad del « ser formoseño », en este caso de los jóvenes. No obstante, incluso estas reivindicaciones dejan entrever la persistencia de las estigmatizaciones naturalizadoras, pues los qom se asocian a su condición de « raza » - de la cual, justamente, no participarían los blancos, que no suelen ser denominados con ese término. Además, el hecho de que se presente como utopía una « Formosa para todos », deja entrever que aún hay en ella sectores que han permanecido excluidos y con menos posibilidades de « expresarse en libertad », tal es el caso de los indígenas. Justamente, es únicamente el discurso de Romualdo el que hará explícitas estas relaciones de poder y desigualdad, cuando en su texto menciona el « sometimiento de tantos años » de su cultura. 


\section{Genealogías y producción de sentido de una producción cultural híbrida}

El CD aquí descripto se constituye en una producción de carácter híbrido que remite a distintas influencias culturales, promoviendo sentidos diversos e incluso contradictorios. Por un lado, el material visual y los discursos escritos que lo acompañan, parecen tener la intención estratégica de remarcar cierta autenticidad indígena: desde los títulos en lengua vernácula, las alusiones a la « raza » qom y sus vínculos con la « naturaleza », hasta la imagen corporal de Romualdo con su instrumento tradicional. Incluso algunos de estos elementos evidencian una cierta exotización de lo indígena que remarcaría su otredad, como la postura de piernas cruzadas y el pelo largo, a la manera de un « indio hiperreal » que, como sostiene Ramos (1998), no concuerda con los indígenas contemporáneos.

Por otro lado, vimos también que los estilos e instrumentaciones musicales utilizadas, evidencian un carácter híbrido, reconocido por Romualdo en la combinación de temas « ancestrales » $\mathrm{y}$ 《 recientes », y por Irala, en su apreciación de que este CD implica una « mixtura » y « fusión », en la que además participó activamente - cuestiones que sin embargo no son visibilizadas en la gráfica y textualidad que acompaña el CD.

Así, consideramos que esta obra da cuenta de un intento estratégico de la Subsecretaría de Cultura provincial por reconocer el patrimonio musical de los tobas, aunque bajo dos condiciones: subsumiéndolo a una identidad cultural formoseña mayor de carácter multicultural, como se evidencia en la elección de una música de « mixtura » o « fusión », encarnada por un « ejemplo para toda la juventud formoseña »; y operativizando ese reconocimiento bajo la guía de un blanco, en este caso la figura del productor y músico criollo que aportaría, según sus palabras, sus modos « más elaborados » a esta « raza qom » ${ }^{16}$.

Para Romualdo, en cambio, la posibilidad de grabar este CD operó como una táctica que le permitió introducir su voz en las políticas culturales oficiales de la provincia, a través de estas músicas que « expresan el pensamiento » de su pueblo y también, aunque mucho más tímidamente, denuncian su « sometimiento ». De este modo, pudo aumentar también su « capital simbólico »y legitimarse como « músico toba », promocionando y difundiendo su música frente a audiencias blancas así como a gestores de políticas culturales públicas nacionales y globales, que comenzaron a convocarlo junto con Ema para participar en diferentes eventos ${ }^{17}$. Asimismo, a partir de este capital simbólico,

16. Una estrategia oficial similar aprecimos en relación a proyectos de realización audiovisual presentados por Romualdo a la Subsecretaría de Cultura provincial, pues le proponían trabajar bajo la supervisión de un blanco.

17. Si bien utilizamos las nociones de Bourdieu (1967) sobre capital cultural, social y simbólico, no retomamos aquí la totalidad de conceptos y relaciones involucrados en su « teoría del campo cultural ». Esto se debe a que el énfasis de este artículo está puesto en analizar la producción de un músico toba como resultado de un agente que, circulando 
también se le abrió la posibilidad de acceder a otros capitales socio-económicos, pues aunque nunca recibió paga alguna por la grabación de su CD, sí pudo incorporarse a la Subsecretaría de Cultura con un trabajo remunerado, además de su cargo docente, y pudo acceder también a viajes a otras ciudades del país, encarando nuevos contactos para futuras actuaciones. Esta situación lo diferencia de otros jóvenes de su edad que no pueden acceder a este tipo de recursos y experiencias, como por ejemplo los músicos del Evangelio, quienes limitan sus actuaciones y difusión de sus CDs a las iglesias indígenas locales $\mathrm{y}$, en algunos casos, de provincias o paises vecinos, como Paraguay. Así, tanto por el tipo de música que realiza Romualdo como por sus estudios previos y los recursos económicos a los que hoy puede acceder, él solía auto-reconocerse como « un poco diferente » de los otros jóvenes tobas que hoy son sus vecinos del Barrio Nam Qom. De hecho, tal vez como una metáfora encarnada de su peculiar posición social, él vive sólo en una casa situada en los límites del barrio $^{18}$, sobre la ruta provincial que lo conecta con la ciudad capital de Formosa.

Finalmente, consideramos que es importante realizar unas breves reflexiones sobre aquellas expresiones musicales tobas que no aparecen en el CD de Romualdo, los cantos chamánicos, tan importantes dentro de la cosmovisión y rituales de estos y otros grupos chaqueños. En este sentido, cabe recordar que el chamán recibe el poder por medio de cantos que le ofrecen los seres no humanos poderosos (jaqa'a), a través de sueños, visiones o encuentros (Ruiz 1978-1979; Wright 2008), y estos seres, mayormente «padres » $\mathrm{o}$ « madres » de diferentes especies animales o espacios, pasan a convertirse en sus « compañeros », en « aquellos con quienes habla » o ltaGaiaGawa. Así, en uno de los rituales más difundidos del chamán como es el tratamiento de enfermedades, la cura se efectuaba a través del canto, el diálogo con el compañero no humano poderoso y con el paciente, los gestos del soplo y la succión del mal que produce el malestar. En la obra de Romualdo no existen referencias explícitas a cantos chamánicos, y tampoco sobre el posible rol de los sueños o las visiones en la composición de sus músicas, tradición que en cambio sí perduraba en muchos músicos evangélicos (Citro 2009). De hecho, en una de nuestras charlas, Romualdo reconocía que « algunos dicen que sueñan sus cantos... », pero que a él eso nunca le había

por diferentes campos (como son las comunidades aborígenes y el movimiento de iglesias del Evangelio, los distintos agentes e instituciones del gobierno provincial, los festivales artísticos y las escuelas) ha establecido diversas relaciones y acumulado un determinado capital cultural y simbólico, y no tanto en delimitar el conjunto de posiciones y relaciones de fuerza específicas que constituyen a cada uno de estos campos.

18. Si bien Romualdo vive rodeado de algunos vecinos que a la vez son familiares suyos (y son también quiénes cuidan su casa cuando viaja), él permanece soltero, lo cual no es muy común entre los tobas de su edad. Esta situación de no tener una familia que mantener, sumada al hecho de que posee dos trabajos remunerados, lo colocan en una posición económica un poco más ventajosa que el resto. 
sucedido. Es importante destacar que la entonación de estos cantos aún posee su propia eficacia performativa, es decir, ejecutarlos es un acto que encarna el poder de los seres no humanos, por tanto, implica aceptar recibir y operar con ese peculiar poder o haloik. En contraste, Romualdo no está interesado por incursionar en estas significaciones y usos de la música toba chamánica. $\mathrm{Su}$ preocupación se centra fundamentalmente en la «transmisión», en documentar y « preservar» otros cantos y ejecuciones instrumentales antiguas, a través de las visitas que suele realizar a ancianos de diferentes comunidades que aún recuerdan esas expresiones, y en tomar de allí la inspiración para sus nuevas composiciones. Suele enfatizar así en el sentido identitario que hoy le provee su práctica musical y no tanto en sus aspectos rituales. En este sentido, cabe preguntarse también si el canto chamánico no estaría constituyéndose hoy en el límite a aquello que sería « espectacularizable » para los tobas contemporáneos. Además, en tanto la gran mayoría de los tobas se ha convertido al evangelismo, que históricamente ha sido muy crítico del chamanismo, la grabación en un CD y/o la puesta en escena de un canto de este tipo en un espectáculo, habría implicado mayores tensiones y potenciales conflictos con los miembros de las comunidades, de hecho el $\mathrm{Nmi}$ o los toques de nvique ya resultaban bastante conflictivos para muchos tobas evangélicos, por estar asociado a la seducción de las fiestas del pasado ${ }^{19}$.

\section{Conclusiones}

El CD analizado da cuenta del tipo de políticas culturales que el gobierno formoseño ha puesto en práctica en los últimos años, con la intención estratégica de reelaborar los imaginarios identitarios de la provincia, incluyendo y revalorizando el componente indígena como parte de una renovada concepción identitaria multicultural. Así, en estas políticas culturales se pone de manifiesto aquella utilización de la cultura como un « recurso » para intervenir en el espacio público e intentar legitimar este nuevo imaginario identitario provincial. En términos estéticos, esta estrategia oficial promueve producciones artísticas que apelan a múltiples marcas culturales, adquiriendo así un carácter de hibridez ${ }^{20}$.

19. De manera similar, interpretamos también la recomendación de Romualdo y Ema de no incluir la temática del canto chamánico en un libro de difusión sobre músicas y danzas tobas que estamos preparando actualmente junto con ellos y otros maestros tobas formoseños.

20. En este sentido, otra producción híbrida que hemos analizado recientemente (Citro y Torres Agüero 2014), es la presentación del año 2011 de la delegación oficial de la provincia en el «Festival Nacional de Folklore de Cosquín » (considerado el festival nacional más importante de Argentina), con la obra « Formosa, puerta norte a mi Argentina », ejecutada por el Ballet Folklórico provincial y diversos grupos musicales, en tanto esta obra incluyó, por primera vez en la historia de ese Ballet, motivos coreográficos que intentaban representar a los indígenas de la región. 
Consideramos que en estos procesos de hibridación de las músicas indígenas, pueden advertirse tres grandes tendencias que atraviesan el caso analizado pero que también pueden hallarse en muchas de las expresiones de otros pueblos indígenas de la región.

En primer lugar, se aprecian transformaciones que parecen estar destinadas a acercar o adaptar estas expresiones a las sensibilidades estéticas de las nuevas audiencias que las consumen, al « gusto del mercado », como nos decía Romualdo. De ahí, como vimos, el recurso de incorporar estructuras de los géneros musicales y timbres sonoros más difundidos, hibridizándolos con las estructuras melódicas e instrumentos nativos. Asimismo, estas adaptaciones suelen involucrar la espectacularización de expresiones cuyos fines eran originariamente rituales y/o festivos, tal es el caso de los toques de nvique y los cantos-danzas del $\mathrm{Nmi}$, que formaban parte de los encuentros festivos entre los jóvenes solteros y propiciaban sus vínculos sexuales.

En segundo lugar, encontramos que paralelamente a estas incorporaciones y transformaciones, se suelen invisibilizar o incluso excluir aquellos elementos que confrontarían las sensibilidades hegemónicas, en tanto podrían ser percibidos como « aburridos » o poco « atrayentes » para estas nuevas audiencias, tal es lo que habría acontecido con el uso tradicional del nvique como instrumento solista, sin el acompañamiento de otros instrumentos que refuercen las marcaciones rítmicas. Otro importante elemento que es invisibilizado en la obra de Romualdo, es la relación entre música y chamanismo. No obstante, esta exclusión se vincularía con los potenciales conflictos al interior de su propia comunidad así como por las significaciones fundamentalmente identitarias que él hoy otorga a la práctica musical y que van más allá de sus dimensiones rituales. En este sentido, su educación terciaria y luego su desempeño como profesor de música, operaron en su biografía como prácticas de profesionalización que también habrían incidido en sus elecciones estéticas, excluyendo a estas otras músicas que poseen fuertes y controvertidas connotaciones religiosas entre los qom.

En tercer lugar, dentro de estas producciones culturales híbridas, encontramos otras reelaboraciones que parecen estar destinadas a visibilizar ciertos « índices » que marcarían la otredad o exotismo de estas expresiones, remarcando su carácter « originario », « ancestral », constituyéndolas así en objetos legítimos para las actuales políticas culturales y patrimoniales promovidas globalmente. En estos procesos de marcación de la otredad, suele advertirse aquello que Bhabha (2002) denomina « fetichizaciones exotizantes », tal es lo que se aprecia en el caso del $\mathrm{CD}$ analizado, en la imagen corporal que se eligió para la tapa y las alusiones a la « raza qom ». No obstante, vimos también cómo los performers pueden intervenir activamente en esta « instrumentación del exotismo » (Ramos 1998) y utilizarla tácticamente, por ejemplo, cuando Romualdo enfatiza en las relaciones « armoniosas » de los qom con la « naturaleza », intentado articular así su concepción de la cosmovisión cazadora-recolectora toba con ciertos 
contenidos afines de la concepción new age. En este sentido, y como también ha señalado Zuñiga (2008) para expresiones indígenas de México, cada vez son más habituales este tipo de reelaboraciones en torno a las significaciones y finalidades de las músicas y danzas rituales amerindias, en el contexto de la difusión de estas « nuevas espiritualidades » transnacionales.

En conclusión, a través de nuestro estudio, hemos buscado reflexionar sobre las complejas transformaciones socio-culturales que hoy viven los pueblos amerindios, a partir del análisis de algunas de sus expresiones musicales contemporáneas. Así, pretendimos destacar también la importancia de abordar las músicas amerindias, en tanto éstas históricamente han sido una parte fundamental de la cultura y la vida social de estos pueblos, aunque muchas veces en los estudios antropológicos han quedado relegadas a simples alusiones al canto y la danza (pero sin describir los modos en que se practicaban) o, en el otro extremo, a transcripciones y análisis musicológicos que no siempre nos permitían apreciar los usos sociales y políticos así como el potencial de sentidos culturales que se pone en juego en la ejecución musical. Finalmente, a partir de este trabajo, subrayamos los aportes que el estudio antropológico de la música también provee para el abordaje de las políticas culturales y su papel en la construcción y legitimación de imaginarios identitarios, en el contexto de las complejas y a menudo conflictivas relaciones entre los grupos indígenas, el Estado y los diferentes sectores de la sociedad mayor. *

* Manuscrit reçu en juin 2014, accepté pour publication en février 2015.

\section{Referencias citadas}

Anderson Benedict

1993, Comunidades imaginadas. Reflexiones sobre el origen y la difusión del nacionalismo, Fondo de Cultura Económica, México.

AnTHIAs Floya

2001, " New hybridities, old concepts: the limits of "culture" ", Ethnic and racial studies, 24 (4), p. 619-641.

BARTH Fredrik

1976, Los grupos étnicos y sus fronteras. La organización social de las diferencias culturales, Fondo de Cultura Económica, México.

BARTolomé Miguel A.

1987, « Afirmación estatal y negación nacional. El caso de las minorías nacionales en América Latina », Suplemento antropológico, 22 (2), p. 743-782.

Bнавна Homi

2002, El lugar de la cultura, Manantial, Buenos Aires. 
BAUMAN Richard and Charles BRIGGS

1996, « Género, intertextualidad y poder social », Revista de investigaciones folklóricas, 11, p. $78-108$.

BAYARDO Rubens

2008, « Políticas culturales: derroteros y perspectivas contemporáneas », Revista de investigaciones políticas y sociológicas, 7 (1), p. 17-29.

BÉHAGUE Gerard

1994, « Hacia un enfoque etnomusicológico para el análisis de la música popular », in Irma Ruiz, Elisabeth Roig y Alejandra Cragnolini (eds.), Procedimientos analíticos en musicología. Actas de las IX Jornadas argentinas de musicología y VIII Conferencia anual de la AAM, Instituto Nacional de Musicología Carlos Vega, Buenos Aires, p. 303-318.

BLACKING John

1985, « Movement, dance, music, and Venda girls' initiation », in Paul Spencer (ed.) Society and the dance. The social anthropology of process and performance, Cambridge University Press, Cambridge, p. 64-99.

Bourdieu Pierre

1967, « Campo intelectual y proyecto creador », in Marc Barbut, Pierre Bourdieu y Maurice Godelier, Problemas del estructuralismo, Siglo XXI, México, p. 135-182.

Braunstein José

1983, Algunos rasgos de la organización social de los indígenas del Gran Chaco, Facultad de Filosofía y Letras, Universidad de Buenos Aires, Buenos Aires.

Cámara De Landa Enrique

2006, Entre Humahuaca y La Quiaca. Mestizaje e identidad en la música de un carnaval andino, Universidad de Valladolid, Valladolid.

CARDIN Lorena

2013, « La comunidad qom Paotae Napoqna Navogoh (La Primavera) y el proceso de lucha por la restitución de su territorio », ponencia presentada en la X Jornadas de sociología de la universidad de Buenos Aires.

Citro Silvia

2003, Cuerpos significantes. Una etnografia dialéctica con los toba takshik. tesis de doctorado de Antropología, Facultad de Filosofía y Letras, Universidad de Buenos Aires.

Citro Silvia y Adriana Cerletti

2009, " "Aboriginal dances were always in rings..." Music and dance as a sign of identity in the Argentine Chaco », Yearbook for traditional music, 41, p. 138-165.

Citro Silvia y Soledad Torres Agüero

2012, «Es un ejemplo no solamente para los de su raza qom sino para toda la juventud formoseña. El patrimonio cultural inmaterial y la controvertida política formoseña », RUNA, 33 (2), p. 157-174.

Clifford James

1994, « Diasporas », Cultural anthropology, 9 (30), p. 302-338. 


\section{Coelho Teixeira}

2000, Diccionario crítico de política cultural: cultura e imaginario, Conaculta/Iteso/ Secretaría de Cultura, Gobierno de Jalisco, México.

Crespo Carolina, Flora Losada y Alicia Martín

2007, Patrimonio, políticas culturales y participación ciudadana, Editorial Antropofagia, Buenos Aires.

\section{De Certeau Michael}

1988, The practice of everyday life, University of California Press, Berkeley/Los Angeles.

Escobar Arturo, Sonia Álvarez y Evelina Dagnino

2001, « Introducción: lo cultural y lo político en los movimientos sociales latinoamericanos », in Arturo Escobar, Sonia Álvarez y Evelina Dagnino (eds.), Política cultural y cultura política. Una nueva mirada sobre los movimientos sociales latinoamericanos, Taurus/Icanh, Bogotá, p. 26-31.

FRITH Simon

1987, « Hacia una estética de la música popular », in AAVV: Las culturas musicales. Lecturas de etnomusicología, Editorial Trotta, Madrid.

GARCIA Miguel Ángel

1999, « En torno a las ideas pilagá del origen y la transmisión de cantos », Música e investigación, 5, p. 33-46.

García CANClini Nestor

1987, Políticas culturales en América Latina, Grijalbo, México.

GRÜNER Eduardo

2002, El fin de las pequeñas historias. De los estudios culturales al retorno (imposible) de lo trágico, Norma, Buenos Aires.

GruZINSKI Serge

2000, El pensamiento mestizo, Paidós Ibérica, Barcelona.

Guigère Hélène

2006, « Vues anthropologiques sur le patrimoine culturel immatériel. Un ancrage en basses Andaloise », Anthropologie et sociétés, 30 (2), p. 107-127.

HANNERZ Ulf

1996, « Fluxos, fronteiras, hibridos: palavras-chave da antropologia transnacional », Mana, 3 (1), p. 7-39.

IÑIGO CARRERA Valeria

2006-2007, « Apuntes para pensar el clientelismo entre los tobas del este formoseño: el torno a programas sociales de empleo y sujetos políticos colectivos », Cuadernos del Instituto nacional de antropología y pensamiento latinoamericano, 21, p. 91-100.

JAMESON Frederic

1991, El posmodernismo o la lógica cultural del capitalismo avanzado, Paidos, Barcelona. 
LACARrieu Mónica

2000, « Construcción de imaginarios locales e identidades culturales en la mundialización ", in Seminario de nuevos retos y estrategias de las políticas culturales frente a la globalización, Institut d'estudis Catalans, Barcelona.

LACLAU Ernesto

1996, Emancipación y diferencia, Ariel, Buenos Aires.

MenNelli Yanina

2007, Un abordaje de la performance de contrapunto de coplas « hombre » $y$ « mujer » en el carnaval humahuaqueño, tesina para Licenciatura en Antropología Orientación Etnolingüística, Universidad Nacional de Rosario, Rosario.

Ochoa Gautier Ana Maria

2002, « Políticas culturales, academia y sociedad», in Daniel Mato (coord.), Estudios y otras prácticas intelectuales latinoamericanas en cultura y poder, CLACSO/ CEAP/FACES, Universidad Central de Venezuela, Caracas.

PRATS Lorenc

1997, Antropología y patrimonio, Ariel, Barcelona.

RAmos Alcida

1998, Indigenism. Ethnic politics in Brazil, Wisconsin University Press, Madison.

RoIG Elizabeth

1996, « El coro toba Chelaalapi. Un bolsón aislado de música tradicional », Revista argentina de musicología, 1, p. 71-80.

RuIz Irma

1978-1979, « Aproximación a la relación canto-poder en el contexto de los procesos iniciáticos de las culturas indígenas del Chaco central », Scripta ethnologica, 5 (2), p. 157-169.

Ruiz Irma y Silvia CiTRo

2002, « Toba », in Diccionario enciclopédico de la música española e hispanoamericana, Sociedad General de Autores y Editores de España, Madrid, 10 vol., p. 308-315.

Salamanca Carlos y Florencia Tola

2008, «Formas contemporáneas de la acción política toba a partir del análisis de las estrategias relacionales qom y de la capacidad de acción », in José Braunstein y Norma Meichtry (eds.), Liderazgo, representatividad y control social en el Gran Chaco, Editoral Universitaria de la Universidad Nacional del Nordeste, Corrientes, p. 147-156.

SEGAto Rita

1999, « Identidades políticas/alteridades históricas: una crítica a las certezas del pluralismo global », Anuario antropológico, 97, p. 161-196.

SPIVAK Gayatri

1987, In other worlds. Essays in cultural politics, Methuen, Nueva York. 
TAussig Michael

1987, « Orden y desorden en ritos curativos neocoloniales: Brecht, Benjamín y el desorden mismo », Revista de antropología, 3 (1), p. 5-20.

TuRINO Thomas

1999, « Signs of imagination, identity, and experience. A Peircian semiotic theory for music », Ethnomusicology, 43 (2), p. 221-255.

ViVALDi Ana

2008, «Un indio tiene que pagar », Violencia y disputas en la construcción de subjetividades indigenas, Calacs, Vancouver.

Wright Pablo

2008, Ser-en-el-sueño. Crónicas de historia y vida toba, Biblos, Buenos Aires.

YudicE George

2002, El recurso de la cultura. Usos de la cultura en la era global, Gedisa, Barcelona.

ZizeK Slavoj

1998, « Multiculturalismo o la lógica cultural del capitalismo multinacional », in Fredric Jameson, Slavoj Zizek, Estudios culturales. Reflexiones sobre el multiculturalismo, Paidós, Buenos Aires.

\section{ZúÑIGA Cristina Gutiérrez}

2008, « La danza neotradicional como oferta espiritual en la estantería exotérica new age », in Kali Argyriadis, Renée de la Torre, Cristina Gutiérrez Zúñiga y Alejandra Aguilar Ros (coord.), Raíces en movimiento. Prácticas religiosas tradicionales en contextos translocales, Centro de estudios mexicanos y centroamericanos, México, p. 363-392. 